\title{
POTENSI OBYEK WISATA ALAM AIR TERJUN ENTOBA DI DESA NYANGGAI KECAMATAN PINOH SELATAN KABUPATEN MELAWI
}

\author{
(Potential Natural Tourist Objects of Entoba Waterfall in Nyanggai Village South Pinoh \\ District, Melawi Regency)
}

\author{
Oky Wahyu Saputra, Sarma Siahaan, Tri Widiastuti \\ Fakultas Kehutanan Universitas Tanjungpura. Jalan Imam Bonjol Pontianak 78124 \\ Email: okywahyusaputra08@gmail.com
}

\begin{abstract}
Assessment of natural tourist attraction objects is a systematic and balanced process or activity to collect information about everything that is unique and has high attractiveness value for tourists who come to a certain place and area. This study aims to obtain the value of tourism objects in Nyanggai Village, South Pinoh District, Melawi Regency, West Kalimantan Province, especially for natural tourism of Entoba Waterfall. The method used in this study is a survey method with interview techniques and the tool used in data collection is a questionnaire. The results of the calculation of each assessment criteria based on the 2003 ODTWA PHKA development standard, the assessment of each criterion obtained an average value of 269.14. Entoba waterfall area gets a bad score $(C)$ which means the Entoba waterfall area is not potential to be developed as a natural tourist spot. The local government is expected to optimally assist and facilitate the community in planning the development and management of the natural attractions of Entoba Waterfall as well as increasing access to locations and other facilities intensively to the existence of Entoba Waterfall, both formally and informally.
\end{abstract}

Keywords: Entoba Waterfall, Nyanggai Village, Potential Natural Tourism Objects.

Abstrak

Penilaian obyek daya tarik wisata alam adalah suatu proses atau kegiatan yang sistematis dan seimbang untuk mengumpulkan informasi tentang segala sesuatu yang unik dan bernilai daya tarik tinggi bagi wisatawan yang datang ke suatu tempat dan daerah tertentu. Penelitian ini bertujuan untuk mendapatkan nilai obyek wisata di Desa Nyanggai Kecamatan Pinoh Selatan Kabupaten Melawi Provinsi Kalimantan Barat khususnya untuk wisata alam Air Terjun Entoba. Metode yang digunakan dalam penelitian ini adalah metode survey dengan teknik wawancara dan alat yang digunakan dalam pengumpulan data adalah kuesioner. Hasil perhitungan setiap kriteria penilaian berdasarkan standar pengembangan ODTWA PHKA 2003, penilaian setiap kriteria diperoleh nilai rata-rata sebesar 269,14. Kawasan air terjun Entoba mendapat nilai buruk $(C)$ yang berarti kawasan air terjun Entoba tidak potensial untuk dikembangkan sebagai tempat wisata alam. Pemerintah daerah diharapkan secara optimal membantu dan memfasilitasi masyarakat dalam merencanakan pengembangan dan pengelolaan objek wisata alam Air Terjun Entoba serta meningkatkan akses lokasi dan fasilitas lainnya secara intensif terhadap keberadaan Air Terjun Entoba, baik formal maupun informal.

Kata Kunci : Air Terjun Entoba, Desa Nyanggai, Potensi Obyek Wisata Alam.

\section{PENDAHULUAN}

Desa Nyanggai merupakan kawasan yang terdapat di Kecamatan Pinoh Selatan, Kabupaten Melawi, Provinsi Kalimantan
Barat. Desa Nyanggai memiliki topografi yang berbukit-bukit serta memiliki luas wilayah sekitar $67 \mathrm{~km}^{2}$ atau 6,96\% yang terbagi menjadi empat Dusun yaitu Dusun 
Nanga Nyanggai, Dusun Laman Lanih, Dusun Tanjung Betikal, Dusun Laman Rahan. Berdasarkan Keputusan Mentri Lingkungan Hidup dan Kehutanan Republik Indonesia dengan nomor SK. 4014/MENLHK-PSKL/PKPS/PSL

0/4/2019 tentang pemberian hak pengelolaan hutan desa kepada lembaga pengelolaan hutan Desa Nyanggai seluas \pm 1.125 Hektar yang berada pada kawasan hutan lindung di Desa Nyanggai Kecamatan Pinoh Selatan Kabupaten Melawi Provinsi Kalimantan Barat. Desa Nyanggai memiliki potensi wisata alam yang belum diketahui keberadaanya oleh sebagian masyarakat luas yaitu Air Terjun Entoba. Air Terjun Entoba merupakan salah satu obyek wisata yang ada di Desa Nyanggai secara geografis berada pada titik koordinat $0^{\circ} 34^{\prime} 10,874-0^{\circ} 39^{\prime} 50,938 \mathrm{LS}$ dan $111^{\circ} 47^{\prime} 38,6 \quad-111^{\circ} 56^{\prime} 47,628$ BT. Obyek wisata ini dikelola oleh pihak masyarakat Desa Nyanggai yang telah ada tahun 2008. Eksistensi yang dimiliki obyek wisata Air Terjun Entoba cukup tinggi karena merupakan wisata alam yang telah lama ada di Desa Nyanggai tepatnya di Kecamatan Pinoh Selatan, Kabupaten Melawi. Potensi wisata alam ini menarik untuk dikunjungi karena banyak keindahan alamnya seperti air trjun, flora dan fauna serta berbagai keindahan alam lainnya, namun sampai saat ini belum ada intansi terkait yang berminat untuk mengembangkan tempat tersebut sebagai obyek wisata dikarenakan kurangnya informasi yang spesifik mengenai potensi wisata alam secara detail.Untuk mengetahui dan memperjelas dari penelitian ini ada beberapa penelitian terdahulu yang mempunyai kesamaan tentang Penilaian Potensi Obyek Wisata Alam Air Terjun, antara lain: Menurut Rano Karno Siahaan (2018) melakukan penelitian yang berjudul "Penilaian Potensi Obyek Daya Tarik Wisata Alam (ODTWA) Kawasan Mangrove Setapuk di Kelurahan Setapuk Besar Kecamatan Singkawang Utara Kota Singkawang" menyatakan bahwa kriteria penilaian daya tarik wisata mendapat skor sebesar 926,1 dinyatakan nilainya sedang (B), kriteria penilaian aksesbilitas mendapatkan nilai 425 dinyatakan nilainya sedang (B), kriteria kondisi lingkungan sosial ekonomi mendapatkan nilai 950 dinyatakan nilainya sedang (B), kriteria pelayanan masyarakat mendapatkan nilai 142,3 dinyatakan nilainya baik (A), kriteria kondisi iklim mendapatkan nilai 240 dinyatakan nilainya buruk (C), kriteria akomodasi mendapatkan nilai 30 dinyatakan nilainya buruk (C), kriteria sarana dan prasarana penunjang mendapatkan nilai 90 dinyatakan nilainya sedang (B), kriteria ketersediaan air bersih mendapatkan nilai 420 dinyatakan nilainya sedang (B), kriteria keamanan mendapatkan nilai 92 dinyatakan nilainya buruk (C), kriteria hubungan obyek dengan obyek wisata lain mendapatkan nilai 100 dinyatakan nilainya buruk (C), sehingga nilai kelayakan pengembangan kawasan mangrove setapuk sebesar 342 termasuk kedalam kategori cukup layak untuk dikembangkan (B) sebagai obyek wisata alam.

Obyek wisata alam Air Terjun Entoba tentunya harus melakukan pengembangan yang berkelanjutan dalam menjaga eksistensi obyek wisata tetap terjaga dan 
diminati oleh pengunjung. Selain kurangnya informasi mengenai potensi wisata alam dan daya tarik areal tersebut secara detail, pengelolaan dan pemanfaatan potensi yang dilakukan belum maksimal serta kurangnya dukungan baik secara promosi dan informasi mengenai keberadaan obyek wisata Air Terjun Entoba, maka dapat menjadi masalah dalam pengembanganya. Oleh karena itu, perlu dilakukan penelitian dalam menilai potensi dan daya tarik yang ada di kawasan Air Terjun Entoba.

Tujuan penelitian ini adalah untuk mendapatkan nilai potensi obyek wisata alam Air Terjun Entoba yang berada di Desa Nyanggai, Kecamatan Pinoh Selatan, Kabupaten Melawi. Manfaat yang dapat diperoleh dari penelitian ini diharapkan dapat memberikan suatu gambaran informasi mengenai potensi alam yang dapat dijadikan daya tarik wisata Air Terjun Entoba di Kecamatan Pinoh Selatan, Kabupaten Melawi.

\section{METODE PENELITIAN}

Penelitian dilakasanakan di Air Terjun Entoba yang berada di Desa Nyanggai, Kecamatan Pinoh Selatan, Kabupaten Melawi. Waktu pelaksanaan dilapangan selama \pm 4 (empat) minggu, dari tanggal 28 september sampai dengan 21 oktober 2020. Metode yang digunakan adalah metode survey. Penentuan sampel (responden) yang digunakan dalam penelitian ini menggunakan rumus Slovin. Data primer dalam penelitian ini dikumpul dengan melakukan pengamatan langsung dilapangan dan melakukan wawancara secara langsung dengan pengunjung obyek wisata, masarakat serta intansi terkait, pengumpulan data primer untuk kriteria daya tarik wisata dilakukan dengan mengisi kuesioner. Selain itu, pada kriteria aksesbilitas, kondisi sekitar kawasan, akomodasi, sarana dan prasarana penunjang serta ketersediaan air bersih dilakukan pengamatan seara langsung dengan mengacu pada ADO-ODTWA Tahun 2003. Dalam penelitian ini data pendukung yang diperlukan adalah data yang meliputi litelatur, pencatatan data tentang keadaan umum lokasi penelitian dan peta lokasi.

Untuk menentukan jumlah nilai untuk satu kriteria penilaian ODTWA PHKA dapat dihitung dengan persamaan sebagai berikut:

$\mathbf{S}=\mathbf{N} \times \mathbf{B}$

Keterangan:

$\mathrm{S}=$ Skor/Nilai suatu kriteria.

$\mathrm{N}$ = Jumlah nilai-nilai unsur pada kriteria.

$\mathrm{B}=$ Bobot nilai.

Masing-masing kriteria tersebut dalam penilaian terdiri atas unsur dan sumber yang berkaitan. Nilai masing-masing unsur dipilih dari salah satu angka yang terdapat pada tabel kriteria penilaian ODTWA sesuai dengan potensi dan kondisi masingmasing lokasi.

Analisis data dilakukan secara deskriptif dengan metode skoring. Data dianalisis sesuai dengan pedoman Analisis Daerah Operasi Obyek dan Daya Tarik Wisata Alam (ADO-ODTWA) dari Direktorat Jendral Perlindungan Hutan dan Konservasi Alam Tahun 2003 sesuai dengan nilai yang ditentukan untuk setiap kriteria

\section{HASIL DAN PEMBAHASAN} Kriteria Penilaian Obyek Daya Tarik

Berdasarkan hasil perhitungan dari setiap unsur dan sub unsur pada kriteria 
penilaian daya tarik wisata Air Terjun Entoba yang mengacu pada Pedoman Penilaian Objek dan Daya Tarik Wisata Alam PHKA tahun 2003. Hasil penilaian daya tarik wisata didapat dari jawaban kuesioner yang telah diisi oleh responden sebanyak 55 orang responden. Hasil perhitungan secara keseluruhan unsur penilaian daya tarik wisata alam Air Terjun Entoba di Desa Nyanggai, Kecamatan Pinoh Selatan, Kabupaten Melawi dengan kriteria penilaian dan pengembangan daya tarik wisata berbentuk darat disajikan pada Tabel 19, sebagai berikut:

Tabel 19. Hasil Kriteria Penilaian Daya Tarik Air Terjun Entoba (Results of the Criteria for the Attractiveness of Entoba Falls)

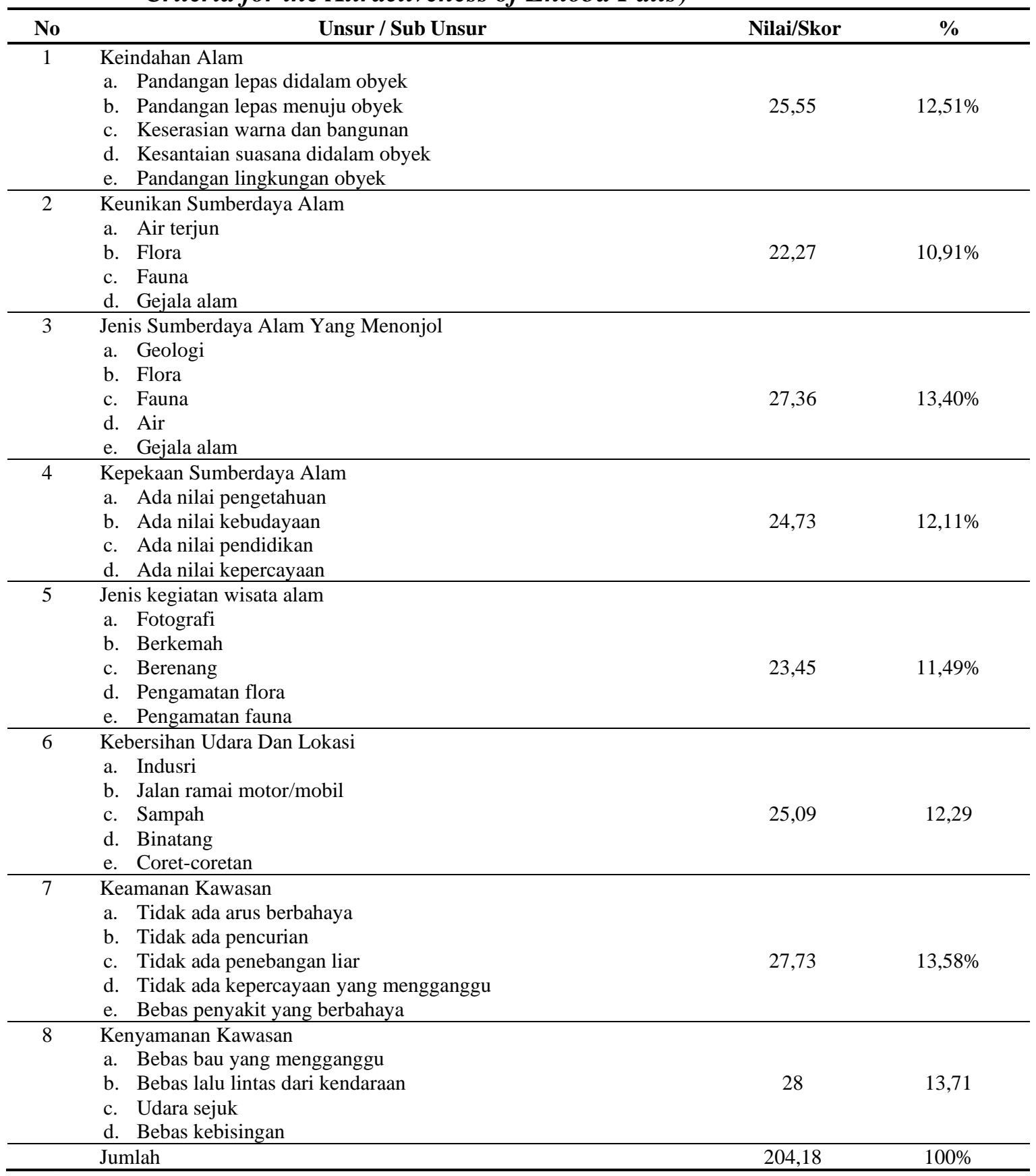


Berdasarakan hasil penelitian dan analisis data yang telah dilakukan pada kriteria penilaian obyek daya tarik wisata alam Air Terjun Entoba di Desa Nyanggai, Kecamatan Pinoh Selatan, Kabupaten Melawi mendapatkan nilai sebesar 204,18 . Nilai yang telah didapat dikalikan dengan bobot nilai kriteria penialaian daya tarik wisata yang berbobot 6 , sehingga didapat nilai pada kriteria penilaian daya tarik wisata Air Terjun Entoba menjadi 1225,09. Nilai yang telah didapat dibandingkan dengan klasifikasi usaha pengembangan obyek wisata alam. Dari hasil perbandingan menunjukan kawasan Air Terjun Entoba memiliki daya tarik kawasan dengan nilai Baik (A) yang berarti berpotensi untuk dikembangkan sebagai tempat tujuan wisata alam. Berdasarkan hasil penelitian dan analisis data dari 55 responden didapat nilai rata - rata 28 dengan presentasi $13,71 \%$. Hasil dari nilai rata - rata tersebut menunjukan kawasan Air Terjun Entoba di Desa
Nyanggai, Kecamatan Pinoh Selatan, Kabupaten Melawi aspek kenyamanan kawasan yang baik dan terjaga sedangkan skor nilai terendah terdapat diunsur dan sub unsur keunikan sumber daya alam sebesar 22,27 dengan presentasi 10,91\%.

\section{Kriteria Penilaian Aksesbilitas}

Berdasarkan hasil penelitian langsung terhadap penilaian kriteria akssbilitas untuk unsur dan sub unsurnya dapat dilihat bahwa jumlah keseluruhan skornya sebesar 60. Hasil penjumlahan tersebut kemudian dibandingkan dengan klasifikasi unsur pengembangan ODTWA PHKA tahun 2003, maka dari hasil perbandingan tersebut menunjukan bahwa kawasan Air Terjun Entoba memiliki aksesbilitas dengan nilai (C) yang berarti buruk untuk dikembangkan sebagai obyek wisata alam. Hasil penelitian untuk kriteria penilaian aksesbilitas disajikan pada Tabel 20, sebagai berikut:

Tabel 20. Hasil Kriteria Penilaian Aksesibilitas (Accessibility Assessment Criteria Results)

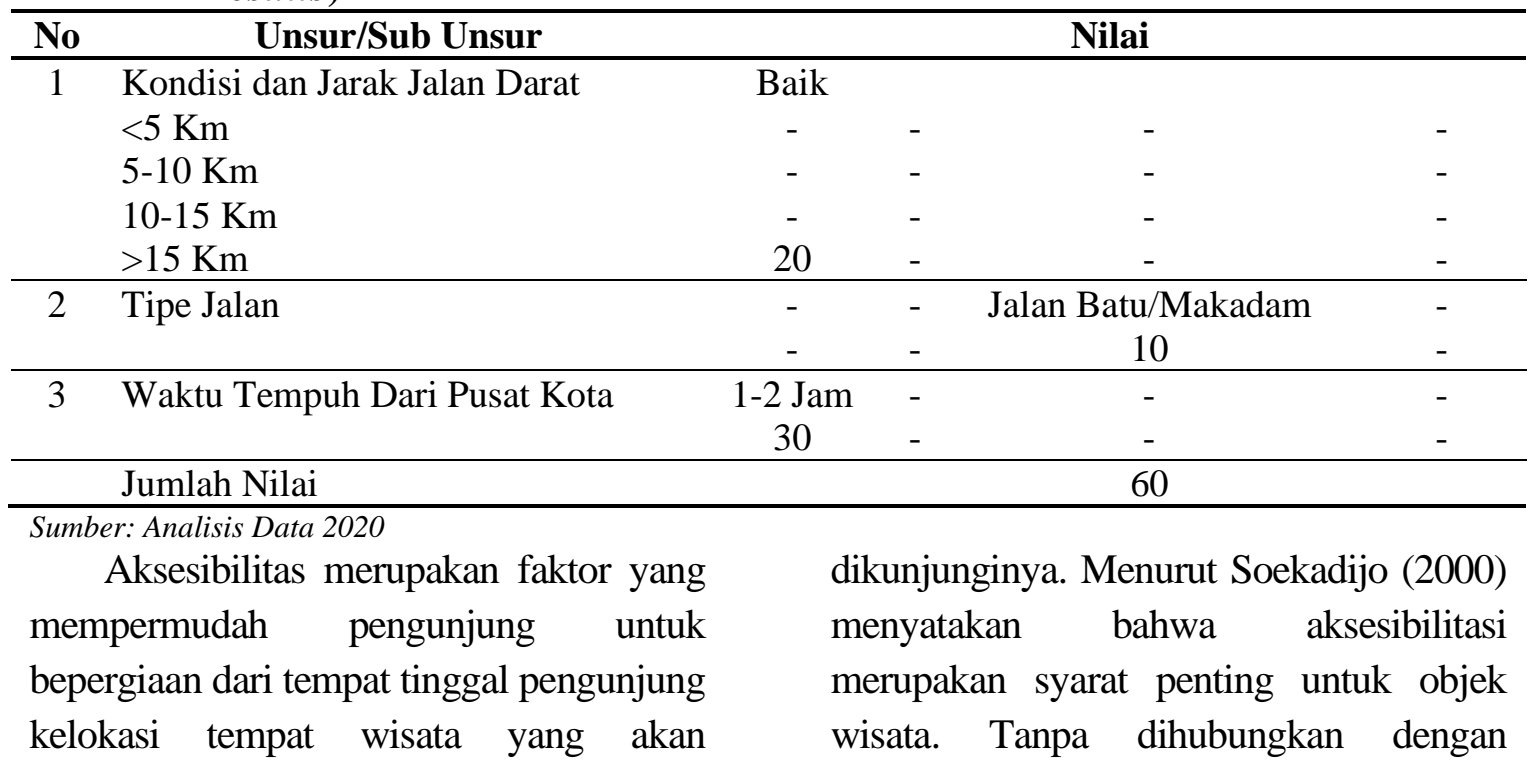


jaringan transportasi tidak mungkin suatu objek mendapatkan kunjungan wisatawan. Berdasarkan hasil pengamatan dilapangan kondisi dan jarak jalan dari pusat kota Nanga Pinoh hingga memasuki Desa Nyanggai dalam kondisi sangat baik dengan lebar jalan rata - rata lebih dari 5 meter. Didalam desa, hampir $70 \%$ jalan sudah diaspal. Namun, ukuran jalan didalam desa relatif lebih kecil, serta beberapa ruas jalan masih belum diaspal dan dalam kondisi rusak. Pada saat musim hujan jalan batu/makadam dapat mengakibatkan jalan menjadi licin bagi pengendara roda 2. Selain faktor kondisi jalan, jarak tempuh dari pusat kota ke kawasan wisata juga menjadi faktor pertimbangan pengunjung. Untuk jarak tempuh ke Desa Nyanggai dari pusat kota Nanga Pinoh diyakini jarak tempuh \pm 67 $\mathrm{Km}$ atau \pm 2 jam perjalananan.

\section{Kriteria Penilaian Kondisi Sekitar Kawasan}

Berdasarkan hasil pengamatan langsung terhadap kriteria penilaian kondisi lingkungan sosial ekonomi dilokasi Air Terjun Entoba memperoleh nilai skor 140. Hasil nilai tersebut dibandingkan dengan klasifikasi unsur pengembangan yang mengacu pada pedoman ODTWA PHKA 2003, Penilaian kriteria kondisi lingkungan sosial ekonomi pada kawasan Air Terjun Entoba disajikan pada Tabel 21, sebagai berikut:

Tabel 21. Hasil Kriteria Penilaian Kondisi Sekitar Kawasan (Results of the Assessment Criteria for Surrounding Area Conditions)

\begin{tabular}{cccccc}
\hline No & Unsur/Sub Unsur & Nilai & & & \\
\hline 1 & Tata Ruang Wilayah & Ada dan sesuai & - & - & - \\
& & 30 & - & - & - \\
\hline 2 & Status Lahan & Hutan Negara & - & - & - \\
& & 30 & - & - & - \\
\hline 3 & Mata Pencaharian Penduduk & - & - & Petani/Nelayan & - \\
& & - & - & 20 & - \\
\hline 4 & Pendidikan & Sebagian besar lulusan & - & - & - \\
& & SLTA keatas & & & - \\
& & 30 & - & - & - \\
5 & Tanggapan Masyarakat Terhadap & Sangat Mendukung & - & - & -
\end{tabular}

Sumber: Analisis Data 2020

Berdasarkan hasil pengamatan dilapangan, kriteria kondisi sekitar kawasan mendapatkan nilai 140. Hasil nilai tersebut dibandingkan dengan klasifikasi unsur pengembangan menunjukan kriteria kondisi sekitar kawasan dikategorikan baik (A) untuk dikembangkan menjadi obyek wisata

140

alam. Desa Nyanggai dengan luas $67 \mathrm{Km}^{2}$ atau $6,96 \%$ dengan jumlah penduduk 745 jiwa yang terdiri dari 367 Orang laki - laki dan 378 perempuan dengan jumlah kepadatan penduduk 13 Jiwa $/ \mathrm{km}^{2}$. Berdasarkan Keputusan Mentri Lingkungan Hidup dan Kehutanan Republik Indonesia dengan 
nomor SK. 4014/MENLHKPSKL/PKPS/PSL 0/4/2019 tentang pemberian hak pengelolaan hutan desa kepada lembaga pengelolaan hutan Desa Nyanggai seluas \pm 1.125 (Seribu Seratus Dua Puluh Lima) Hektar yang berada pada kawasan hutan lindung di Desa Nyanggai Kecamatan Pinoh Selatan Kabupaten Melawi Provinsi Kalimantan Barat. Mata pencaharian Sebagian besar penduduk Desa Nyanggai mayoritas bekerja sebagai petani, disamping itu ada juga yang menjadi pedagang dan peternak. Tingkat pendidikan di Desa Nyanggai tergolong rendah. Sarana pendidikan yang ada di Desa Nyanggai hanya ada SD dan SMP. (BPS Kabupaten Melawi). Berdasarkan hasil yang didapat dilapangan, masyarakat yang berpersepsi mengenai tanggapan terhadap pengembangan obyek wisata alam Air Terjun Entoba, masyarakat sangat setujuh dengan dikembangkannya Air Terjun Entoba sebagai obyek wisata alam. Pengembangan obyek wisata alam sebagai daya tarik wisata akan memberikan dampak positif bagi perkembangan pariwisata di Desa Nyanggai, karena akan menambah daya tarik wisata yang ada Desa Nyanggai dan akan membuka lapangan pekerjaan baru bagi masyarakat setempat.Harapan utama masyarakat setempat dengan dikembangkannya daya tarik wisata Air Terjun Entoba dapat meningkatkan perekonomian masyarakat yang dulunya bekerja sebagai petani, pedagang dan lain-lain, sampai yang belum bekerja atau pengangguran dapat beralih profesi di sektor pariwisata.

\section{Kriteria Penilaian Akomodasi}

Unsur-unsur yang dinilai pada kriteria penilaian akomodasi adalah jumlah penginapan dan jumlah kamar. Berdasarkan hasil pengamatan langsung pada penelitiaan kriteria sarana dan prasarana penunjang memiliki nilai skor sebesar 0. Hasil nilai tersebut dibandingkan dengan klasifikasi unsur pengembangan yang mengacu pada pedoman ODTWA PHKA 2003, Hasil penilaian kriteria akomodasi pada kawasan Air Terjun Entoba disajikan pada Tabel 22, sbagai berikut:

Tabel 22. Hasil Kriteria Penilaian Akomodasi (Accommodation Assessment Criteria Results)

\begin{tabular}{ccc}
\hline No & Unsur / Sub Unsur & Nilai / Skor \\
\hline 1 & Jumlah Penginapan & 0 \\
2 & Jumlah Kamar & 0 \\
\hline & Jumlah Nilai Skor & 0 \\
\hline
\end{tabular}

Sumber : Analisis Data 2020

Berdasarkan hasil pengamatan di lapangan dan informasi dari Kepala Desa Nyanggai serta masyarakat setempat bahwa di sekitar Air Terjun Entoba belum terdapat penginapan yang disediakan bagi pengunjung. Pengunjung yang berasal dari luar daerah biasanya menginap di pusat kota Nanga Pinoh karena terdapat banyak penginapan dan akses dari Nanga Pinoh 
ke Air Terjun Entoba dapat di tempuh dengan waktu 2 jam.

\section{Kriteria Penilaian Sarana Dan Prasarana Penunjang}

Sarana dan prasarana penunjang yang di nilai adalah yang berada dalam radius $10 \mathrm{~km}$ dari objek. Berdasarkan hasil pengamatan langsung pada penelitiaan kriteria sarana dan prasarana penunjang memiliki nilai skor sebesar
45. Hasil dari nilai skor tersebut kemudian dibandingkan dengan klasifikasi unsur pengembangan berdasarkan nilai bobot kriteria sarana prsarana penunjang yang mengacu pada pedoman penunjang ODTWA PHKA 2003, sarana dan prasarana penunjang yang terdapat pada kawasan Air Terjun Entoba disajikan pada Tabel 23, sebagai berikut:

Tabel 23. Hasil Kriteria Penilaian Sarana dan Prasarana Penunjang (Results of the Criteria for Assessment of Supporting Facilities and Infrastructure)

\begin{tabular}{|c|c|c|c|c|c|c|}
\hline \multirow{3}{*}{ No } & \multirow{3}{*}{ Unsur/Sub Unsur } & \multicolumn{5}{|c|}{ Macam } \\
\hline & & $>4$ macam & 3 macam & $\begin{array}{c}2 \\
\text { macam }\end{array}$ & $\begin{array}{c}1 \\
\text { macam }\end{array}$ & $\begin{array}{c}\text { Tidak } \\
\text { ada }\end{array}$ \\
\hline & & \multicolumn{5}{|c|}{ Nilai } \\
\hline 1 & $\begin{array}{l}\text { Sarana: } \\
\text { a. Bank } \\
\text { b. Transportasi }\end{array}$ & - & - & 20 & - & - \\
\hline \multirow[t]{2}{*}{2} & $\begin{array}{l}\text { Prasarana: } \\
\text { a. Jaringan air minum } \\
\text { b. Jaringan listrik } \\
\text { c. Jaringan telpon }\end{array}$ & - & 25 & - & - & - \\
\hline & Jumlah & & & 45 & & \\
\hline
\end{tabular}

Sumber : Analisis Data 2020

Berdasarkan hasil perbandingan tersebut menunjukan bahwa sarana dan prasarana penunjang dikawasan Air Terjun Entoba memiliki nilai sedang (B) yang berarti berpotensi untuk di kembangkan menjadi obyek wisata alam. Meskipun nilai sarana dan prasarana penunjang mendapatkan nilai (B), namun masih banyak yang belum tersedia seperti akomodasi, kantor pos, puskemas, rumah makan, pasar, dan toko souvenir sehingga perlu disediakan oleh pemerintah setempat.

\section{Kriteria Penilaian Ketersediaan Air} Bersih

Berdasarkan hasil pengamatan langsung pada penelitiaan kriteria ketersediaan air bersih memiliki nilai skor sebesar 145. Hasil dari nilai skor tersebut kemudian dibandingkan dengan klasifikasi unsur pengembangan berdasarkan nilai bobot kriteria sarana - prsarana penunjang yang mengacu pada pedoman penunjang ODTWA PHKA 2003, disajikan pada Tabel 24, sebagai berikut: 
Tabel 24. Hasil Kriteria Penilaian Ketersediaan Air Bersih (Results of the Clean Water Availability Assessment Criteria)

\begin{tabular}{clcc}
\hline No & \multicolumn{1}{c}{ Unsur/Sub Unsur } & Sub Unsur Penilaian & Nilai \\
\hline 1 & Volume & Banyak & 30 \\
2 & Jarak Sumber Air Terhadap Lokasi Objek & $0-3 \mathrm{Km}$ & 30 \\
3 & Kemudahan Air Dialirkan ke Objek & Sangat Mudah & 30 \\
4 & Kelayakan Konsumsi & Perlu Perlakuan Sederhana & 25 \\
5 & Kontuinitas & Sepanjang Tahun & 30 \\
\hline \multicolumn{2}{r}{ Jumalah Nilai Skor } & & 145 \\
\hline Sumber: Analisis Data 2020
\end{tabular}

Berdasarkan hasil penelitian unsur dan sub unsur ketersediaan air bersih memperoleh skor sebesar 145. Hasil nilai skor tersebut menunjukan bahwa ketersediaan air bersih dikawasan Air Terjun Entoba dapat diklasifikasikan baik (A) untuk di kembangkan sebagai tempat wisata alam.

Air bersih merupakan faktor yang harus tersedia dalam pengembangan suatu tempat wisata baik untuk pengelolaan dan pelayanan. Volume/ketercukupan air pada lokasi Air Terjun Entoba dinilai banyak, jarak sumber air sangat dekat (< $1 \mathrm{Km})$ dan sangat mudah untuk dialirkan. Untuk kelayakan konsumsi umumnya air yang berada disekitar kawasan dibutuhkan perlakuan sederhana yaitu dimasak dahulu dan selalu tersedia sepanjang tahun meskipun kemarau.

Hasil Perhitungan Klasifikasi Unsur Pengembangan Berdasarkan Nilai Bobot Setiap Kriteria Penilaian

Berdasarkan hasil pengamatan dan analisa data yang telah dilakukan, klasifikasi unsur dan sub unsur untuk pengembangan dari (6) enam kriteria penilaian yaitu kriteria daya tarik wisata, kriteria aksebilitas, kriteria kondisi lingkungan sosial ekonomi, kriteria akomodasi, kriteria sarana dan prasarana penunjang serta kriteria ketersediaan air bersih. Nilai dari masing - masing kriteria yang telah diklasifikasikan di jumlahkan sehingga mendapatkan nilai total sebesar 1615,09, maka nilai total yang telah didapat 1615,09 / $6=269,18$.

Berdasarkan hasil yang telah didapat dan diklasifikasikan dengan kelas pengembangan ODTWA PHKA tahun 2003, kawasan Air Terjun Entoba mendapatkan nilai Buruk (C) yang berarti bahwa kawasan Air Terjun Entoba tidak potensial untuk dikembangkan sebagai tempat obyek wisata alam. Hasil penilaian keenam kriteria tersebut disajikan dalam Tabel 25, sebagai berikut: 
Tabel 25. Hasil Perhitungan Setiap Kriteria Penilaian Berdasarkan Standar Baku Klasifikasi Pengembangan ODTWA PHKA tahun 2003 (Calculation Results of Each Assessment Criteria Based on the Classification Standards for the Development of ODTWA PHKA in 2003)

\begin{tabular}{lllll}
\hline No & Kriteria Penilain & Nilai & \multicolumn{2}{l}{ Klasifikasi } \\
\hline 1 & Penilaian Daya Tarik Wisata & 1225,09 & (A) & Baik \\
2 & Penilaian Aksesibilitasi & 60 & (C) & Buruk \\
3 & Penilaian Kondisi Sekitar Kawasan & 140 & (A) & Baik \\
4 & Penilaian Akomodasi & 0 & (C) & Buruk \\
5 & Penilaian Sarana Prasarana & 45 & (B) & Sedang \\
& Pengunjung & & (A) & Baik \\
6 & Penilaian Ketersediaan Air Bersih & 145 & (C) & Tidak Potensial \\
& Skor Total Penilaian 1615,09/6 & 269,18 & & Dikembangkan \\
\hline
\end{tabular}

Sumber : Analisis Data 2020

\section{Kesimpulan}

1. Nilai skor total yang diperoleh dari hasil perhitungan seluruh kriteria penilaian yaitu sebesar 1615,09 / $6=$ 269,18. Masuk kategori (C) yang berarti belum potensial untuk dikembangkan pada saat ini sebagai tempat tujuan wisata alam di Desa Nyanggai Kecamatan Pinoh Selatan Kabupaten Melawi.

2. Hasil penilaian potensi daya tarik wisata Air Terjun Entoba masuk dalam kategori Baik (A) dengan nilai 1225,09, penilaian aksesibilitas masuk kategori buruk (C) dengan nilai 60, penilaian kondisi sekitar kawasan masuk dalam kategori Baik (A) dengan nilai 140, penilaian akomodasi masuk dalam kategori Buruk (C) dengan nilai 0, penilaian sarana prasarana penunjang masuk kategori Sedang (B) dengan nilai 45, penilaian ketersediaan air bersih masuk dalam kategori Baik (A) dengan nilai 145 .

\section{Saran}

1. Diharapkan pemerintah daerah lebih memperhatikan aksesbilitas menuju lokasi Air Terjun Entoba, akomodasi harus diperiotaskan seperti penginapan, sarana prasarana penunjang yang masih belum tersedia di lokasi Air Terjun Entoba.

2. Diharapkan masyarakat maupun pengunjung agar tetap menjaga kelestarian hutan serta potensi yang terdapat pada kawasan Air Terjun Entoba.

\section{DAFTAR PUSTAKA}

[BPS] Badan Pusat Statistik. 2019. Kecamatan Pinoh Selatan Dalam Angka 2019. Melawi : Badan Pusat Statistik Kabupaten Melawi.

[KLKHK] Kementrian Lingkungan Hidup dan Kehutanan. Keputusan Mentri Kehutanan 4014/MENLHKPSKL/PKPS/PSL 0/4/2019 tentang Pemberian Hak Pengelolaan Hutan Desa. Kalbar: UPT KPH Wilayah Melawi.

[PHKA] Perlindungan Hutan Dan Konservasi Alam 2003. Pedoman Analisis Daerah Operasi Obyek Dan Daya Tarik Wisata Alam (ADO-ODTWA). Bogor: Direktorat Jendral Perlindungan 
Hutan dan Konservasi Alam.

[PHKA] 1993. Ukuran Standar Baku Penilaian Pengembangan dan Pemanfaatan Obyek Wisata Alam. Jawa Barat: Komisi Kerjasama Penelitian Dan Pengembangan Obyek Wisata Alam Bogor. Bogor.

Rano Karno Siahaan. 2018. Penilaian Potensi Obyek Daya Tarik Wisata Alam (ODTWA) Kawasan Mangrove Setapuk Dikelurahan Setapuk Besar Kecamatan Singkawang Utara Kota Pontianak. Peronema Forestry Science Journal 6(1) : 25-24

Soekadijo, R. G. 2000. Anatomi Pariwisata. Jakarta: Penerbit PT Gramedia. Pustaka Utama. 